\title{
Subcellular Dynamics of Somatostatin Receptor Subtype 1 in the Rat Arcuate Nucleus: Receptor Localization and Synaptic Connectivity Vary in Parallel with the Ultradian Rhythm of Growth Hormone Secretion
}

\author{
Thomas Stroh, ${ }^{1,2}$ Martine R. van Schouwenburg, ${ }^{1,2}$ Alain Beaudet, ${ }^{1,2}$ and Gloria S. Tannenbaum ${ }^{1,2,3,4}$ \\ ${ }^{1}$ Department of Neurology and Neurosurgery and ${ }^{2}$ Montreal Neurological Institute, McGill University, Montréal, Québec H3A 2B4, Canada, ${ }^{3}$ Department of \\ Pediatrics, McGill University, Montréal, Québec H3H 1P3, Canada, and ${ }^{4}$ Montreal Children’s Hospital Research Institute, Montréal, Québec H3H 1P3, Canada
}

\begin{abstract}
Growth hormone (GH) secretion in male rats exhibits a $3.3 \mathrm{~h}$ ultradian rhythm generated by the reciprocal interaction of GH-releasing hormone (GHRH) and somatostatin (SRIF). SRIF receptor subtypes sst $_{1}$ and sst $_{2}$ are highly expressed in GHRH neurons of the hypothalamic arcuate nucleus (ARC). We previously demonstrated an ultradian oscillation in binding of SRIF analogs to the ARC in relation to GH peaks and troughs. Here we tested the hypothesis that these ultradian changes in SRIF binding are due to differential plasma membrane targeting of sst ${ }_{1}$ receptors in ARC neurons using immunocytochemistry and electron microscopy. We found that $87 \%$ of sst ${ }_{1}$-positive ARC neurons also synthesized GHRH. Subcellularly, $80 \%$ of sst $_{1}$ receptors were located intracellularly and $20 \%$ at the plasma membrane regardless of GH status. However, whereas $30 \%$ of the cell-surface sst $_{1}$ receptors were located perisynaptically or subsynaptically following exposure to high GH secretion, this fraction was increased to $42 \%$ following a GH trough period $(p=0.05)$. Furthermore, the relative abundance of symmetric and asymmetric synapses on sst $_{1}$-positive dendrites also varied significantly, depending on the GH cycle, from approximately equal numbers following GH troughs to 70:30 in favor of symmetric, i.e., inhibitory, inputs after GH peaks $(p<0.02)$. These findings suggest that postsynaptic localization of sst ${ }_{1}$ receptors and synaptic connectivity in the ARC undergo pronounced remodeling in parallel with the GH rhythm. Such synaptic plasticity may be an important mechanism by which sst ${ }_{1}$ mediates SRIF's cyclical effects on ARC GHRH neurons to generate the ultradian rhythm of GH secretion.
\end{abstract}

\section{Introduction}

The secretion of growth hormone (GH) in male rodents exhibits an endogenous ultradian rhythm with major bursts of GH secretion occurring at regular $3.3 \mathrm{~h}$ intervals followed by trough periods of very low or undetectable basal plasma GH levels (Tannenbaum and Martin, 1976). This rhythm is generated through the interaction of two hypothalamic neuropeptides, GH-releasing hormone (GHRH) and somatostatin (SRIF) in the hypophysis and the hypothalamic arcuate nucleus (ARC) (Tannenbaum and Epelbaum, 1999). In the male rat, these two neurohormones are

\footnotetext{
Received Jan. 20, 2009; revised April 23, 2009; accepted May 19, 2009.

This study was supported by Grants MOP-7366 (to A.B.) and MOP-64328 (to G.S.T.) from the Canadian Institutes of Health Research and Grant RGPIN 327327-06 (to T.S.) from the National Science and Engineering Research Council of Canada. M.R.v.S. was funded by the Marco Polo Fonds, Stichting de Korinthiërs, Stipendiafonds, and Groninger Universiteits Fonds; T.S. is supported by a John R. \& Clara M. Fraser Memorial Award by the Faculty of Medicine, McGill University; G.S.T. holds a Career Investigator Award from the Fonds de la Recherche en Santé du Québec. We thank Mariette Lavallée, Qingyi Chen, Marwan Samia, and Zehra Khoja for expert technical assistance and Naomi Takeda for administrative support in the preparation of this manuscript. The provision of GH RIA materials by the National Institute of Diabetes and Digestive and Kidney Diseases and Dr. A. F. Parlow is gratefully acknowledged.

Correspondence should be addressed to Dr. Thomas Stroh, Montreal Neurological Institute, McGill University, 3801 University Street, Montréal, QC H3A 2B4, Canada. E-mail: thomas.stroh@mcgill.ca.

M. R. van Schouwenburg's present address: Donders Institute for Brain, Cognition, and Behaviour, Radboud University Nijmegen Medical Centre, 6525 HR Nijmegen, The Netherlands.

A. Beaudet's present address: Canadian Institutes of Health Research, 0ttawa, 0N K1A 0W9, Canada. D0I:10.1523/JNEUROSCI.0336-09.2009

Copyright $\odot 2009$ Society for Neuroscience $\quad 0270-6474 / 09 / 298198-08 \$ 15.00 / 0$
}

released in reciprocal 3-4 $\mathrm{h}$ cycles from the median eminence into the hypophyseal portal circulation to act upon somatotropes (Tannenbaum and Ling, 1984; Plotsky and Vale, 1985). Furthermore, we have postulated that SRIF is also released into the hypothalamus with a $3.3 \mathrm{~h}$ periodicity (Wagner et al., 1998).

SRIF acts via a family of G-protein-coupled receptors (GPCRs), sst ${ }_{1}-\mathrm{sst}_{5}$, which are differentially distributed throughout the CNS (Csaba and Dournaud, 2001; Olias et al., 2004). ARC GHRH neurons express high levels of sst ${ }_{1}$ and sst $_{2 \mathrm{~A}}$ mRNA (Tannenbaum et al., 1998). Both receptor proteins are present in the ARC, whereas other SRIF receptor subtypes are of low abundance in this area (Hervieu and Emson, 1998; Stroh et al., 2006; Kumar, 2007) (but see also Helboe et al., 1998), consistent with the involvement of $\mathrm{sst}_{1}$ and $\mathrm{sst}_{2}$ in the hypothalamic regulation of $\mathrm{GH}$ secretion (Guo et al., 1996; Zheng et al., 1997; Zhang et al., 1999; Lanneau et al., 2000).

In parallel with the ultradian GH secretion cycle, we found that binding of radiolabeled, non-receptor subtype-selective SRIF analogs to the ARC also oscillates in an ultradian manner; thus, SRIF binding is highest during peaks in GH secretion and lowest during GH troughs (Tannenbaum et al., 1993). This may be due to differential plasma membrane targeting and cellsurface maintenance of SRIF receptors. Indeed, the sst $_{2 \mathrm{~A}}$ receptor subtype rapidly internalizes in response to endogenous SRIF and 
Table 1. Primary antibodies and their dilutions in various applications

\begin{tabular}{llll}
\hline & \multicolumn{2}{l}{ Dilutions } & \\
\cline { 2 - 4 } Primary antibody (source) & Immunohistochemistry & Immunofluorescence & Immuno-EM \\
\hline $\begin{array}{l}\text { Rabbit anti-sst }{ }_{1} \text { [custom (Stroh et al., 2006)] } \\
\text { Sheep anti-GHRH [custom (Tannenbaum et }\end{array}$ & $1: 500$ & $1: 100$ & $1: 100$ \\
$\begin{array}{l}\text { al., 1990)] } \\
\text { Guinea pig anti-VGluT2 (Millipore Bioscience }\end{array}$ & & $1: 1000$ \\
$\quad$ Research Reagents) & $1: 5000$ & $1: 5000$ \\
Mouse anti-VGAT (Synaptic Systems) & $1: 500$ & $1: 200$ \\
\hline
\end{tabular}

exogenously applied agonists in neurons in which it previously localized to the somatodendritic plasma membrane (Dournaud et al., 1998; Csaba et al., 2001; Csaba et al., 2007). However, little is known about mobilization and regulation of sst ${ }_{1}$ in hypothalamic neurons in vivo.

In the present study, we hypothesized that the increase in SRIF binding to the ARC during peaks in $\mathrm{GH}$ secretion may be due, at least in part, to an increase in sst $_{1}$ receptors at the cell surface of GHRH neurons. Moreover, mounting evidence indicates that ARC neurons may respond to changing physiological status of the organism with changes in synaptic connectivity (Parducz et al., 2003). Therefore, we further hypothesized that changes in SRIF receptor targeting in the ARC may be accompanied by variations in the synaptic connectivity of the nucleus. To test these hypotheses, we examined, by electron microscopic immunohistochemistry, the cellular and subcellular localization of $s t_{1}$ receptors in the ARC of male rats at times associated with peaks and troughs of the GH secretion cycle and studied the synaptic contacts of sst ${ }_{1}$-positive ARC neurons at the same time points.

\section{Materials and Methods}

Animals and experimental procedures. Adult male Sprague Dawley rats (200$250 \mathrm{~g}$; Charles River Canada) were individually housed in an isolated room under a $12 \mathrm{~h}$ light, $12 \mathrm{~h}$ dark cycle (lights on: 6:00 A.M.) at $22 \pm 1^{\circ} \mathrm{C}$ and constant air humidity. Purina rat chow (Ralston Purina) and tap water were available ad libitum. Chronic intravenous cannulae were implanted in the external jugular vein under sodium pentobarbital anesthesia $(50 \mathrm{mg} / \mathrm{kg}$, i.p.) using a previously described technique (Tannenbaum and Martin, 1976). After surgery, the rats were directly placed in isolation test chambers with food and water available ad libitum until body weight returned to preoperative levels (usually within $5-7 \mathrm{~d} ; n=6$ animals).

On the day of the experiment, blood samples were withdrawn every 15 min from unanesthetized, free-moving rats starting at 9:00 A.M. until either 11:00 A.M. or 1:00 P.M., when they were anesthetized with an intravenous injection of sodium pentobarbital (35 mg/kg). The times of 11:00 A.M. and 1:00 P.M. were chosen because we previously established that they correspond to typical peak and trough periods of GH secretion, respectively, in male rats maintained under the above photoperiodic conditions (Tannenbaum and Martin, 1976; Tannenbaum and Ling, 1984). One animal each was fixed for electron microscopy by transaortic perfusion (details below) at either 11:00 A.M. or 1:00 P.M. so that in each experiment a pair of animals fixed at these times was compared with each other. All blood samples were immediately centrifuged, and the plasma was separated and stored at $-20^{\circ} \mathrm{C}$ for subsequent $\mathrm{GH}$ assay. To avoid hemodynamic disturbance, the red blood cells were resuspended in normal saline and returned to the animal after removal of the next blood sample.

Additional rats from the same source were housed under the same conditions but not cannulated. They were fixed in the morning (between 9:00 and 10:00 A.M.) by perfusion with $4 \%$ paraformaldehyde (PFA) in $0.1 \mathrm{M}$ phosphate buffer (PB) for immunohistochemical detection of $\mathrm{sst}_{1}$ and vesicular neurotransmitter transporters and for colocalization studies of sst $_{1}$ with the vesicular transmitter transporters $(n=3)$ or GHRH $(n=3)$ by immunofluorescence. No blood samples were withdrawn from these animals. All animal procedures were performed in compli- ance with the guidelines of the Canadian Council on Animal Care and the McGill University Animal Care Committee.

GH assay. Plasma GH concentrations were measured in duplicate by double-antibody RIA using materials supplied by the National Institute of Diabetes and Digestive and Kidney Diseases Hormone Distribution Program. The averaged plasma $\mathrm{GH}$ values are reported in terms of the rat reference preparation (rGH RP-2). The standard curve was linear between 0.62 and $160.0 \mathrm{ng} / \mathrm{ml}$; the least detectable concentration of plasma GH under the conditions used was $1.2 \mathrm{ng} / \mathrm{ml}$. All samples with values of $>160.0$ $\mathrm{ng} / \mathrm{ml}$ were reassayed at dilutions ranging from 1:2 to $1: 10$. The intraassay and interassay coefficients of variation were $7.7 \%$ and $10.7 \%$ respectively, for duplicate samples of pooled plasma containing a mean concentration of $60.7 \mathrm{ng} / \mathrm{ml}$.

Double immunofluorescence. Adult male Sprague Dawley rats (200$250 \mathrm{~g}$ ) were anesthetized with ketamine/xylazine (80/10 mg/kg, i.p.) and perfused transaortically with a freshly prepared solution of $4 \%$ PFA in 0.1 $\mathrm{M} \mathrm{PB}, \mathrm{pH}$ 7.4. Brains were rapidly removed, cryoprotected overnight at $4^{\circ} \mathrm{C}$ in $0.1 \mathrm{M} \mathrm{PB}$ containing $30 \%$ sucrose, and frozen for $1 \mathrm{~min}$ in isopentane at $-40^{\circ} \mathrm{C}$.

Coronal sections (30 $\mu \mathrm{m}$ thick) were cut on a freezing microtome throughout the rostrocaudal extent of the hypothalamus from the preoptic area to the mammillary region and collected in $0.1 \mathrm{M} \mathrm{PB}$. For immunofluorescent double labeling of $s_{1} t_{1}$ with vesicular neurotransmitter receptors, sections were washed twice with $0.1 \mathrm{~m}$ Trizma base-buffered saline (TBS), $\mathrm{pH} 7.4$, and preincubated for $30 \mathrm{~min}$ at room temperature (RT) in a blocking solution containing $3 \%$ normal goat serum (NGS) in TBS. Subsequently, they were incubated overnight at $4^{\circ} \mathrm{C}$ in a mixture of rabbit anti-sst $t_{1}$ and either guinea pig anti-vesicular glutamate transporter subtype 2 (VGluT2) or mouse anti-vesicular GABA transporter protein (VGAT) appropriately diluted in TBS containing $0.05 \%$ Triton X-100 and $0.5 \%$ NGS (for sources and dilutions, see Table 1). Following rinsing with TBS, bound primary antibodies were visualized by incubation in a mixture of Alexa 594 goat anti-rabbit IgG, detecting the anti-sst ${ }_{1}$, and either Alexa 488 goat anti-guinea pig IgG or Alexa 488 goat anti-mouse IgG for the detection of anti-VGluT2 or VGAT, respectively (all diluted 1:800 in TBS, respectively; all purchased from Invitrogen). After final rinsing the sections were mounted onto chrome-alumcoated slides using Aquapolymount (Polysciences). For GHRH/sst ${ }_{1}$ double labeling (for antibody provenance and dilutions, see Table 1), a sequential staining procedure was adopted and NGS was replaced with normal donkey serum in the immunostaining protocol. Briefly, sections were first incubated overnight at $4^{\circ} \mathrm{C}$ with sheep anti-GHRH. The following day, they were rinsed, incubated for $45 \mathrm{~min}$ at RT with Cy2 donkey anti-sheep IgG (Jackson ImmunoResearch) diluted 1:200 in TBS and subsequently incubated overnight at $4^{\circ} \mathrm{C}$ with rabbit anti-sst ${ }_{1}$. The following day, they were rinsed, incubated for $45 \mathrm{~min}$ at RT with Alexa 594 donkey anti-rabbit IgG (Invitrogen), rinsed again, and mounted onto object slides using Aquapolymount. Twocolor confocal $z$-stacks were acquired on a Zeiss LSM 510 in channel mode (Zeiss Canada). Three-dimensional processing was performed using Volocity release 4.0 (Improvision). The resulting images were adjusted for brightness and contrast using Photoshop CS2, and final composites were created in MS Powerpoint 2003.

Stereological analysis of $\mathrm{GHRH} /$ sst $_{1}$ double-labeled cell populations in the $A R C$. For unbiased estimates of the GHRH- and sst $_{1}$-positive cell populations and the proportion of double-positive cells, sections were analyzed by widefield fluorescence microscopy on a Nikon Eclipse E800 microscope (Nikon Instruments) equipped with an $x / y / z$-motorized stage, a color CCD camera (Optronics, Microfire S99808), and appropriate filter sets for Cy2 (excitation: bandpass $480 / 40 \mathrm{~nm}$; dichroic mirror: long-pass $505 \mathrm{~nm}$; emission: bandpass 535/50 nm) and Alexa 594 (excitation: bandpass 560/55 nm; dichroic mirror: long-pass $595 \mathrm{~nm}$; emission: $645 / 75 \mathrm{~nm}$ ).

GHRH- and sst $_{1}$-positive neurons were mapped and counted using the Optical Fractionator probe of StereoInvestigator (version 8.0, MicroBrightField) for systematic random sampling. Images were acquired and 
counts were performed using a $100 \times$ oilimmersion objective (numerical aperture 1.4). Counts were made through levels separated by $180 \mu \mathrm{m}$ throughout the rostrocaudal extent of the ARC from three individual brains. On each section, the outline of the ARC on both sides of the third ventricle was drawn to define two regions of interest (ROIs) per section, which were both analyzed. For the first series of sections, counts were performed using a counting frame size of $25 \times 25 \mu \mathrm{m}$ and a variable grid size to yield five counting frames per ROI. Based on the results from this pilot study, the final counting frame size was adapted to $50 \times 50 \mu \mathrm{m}$, and the grid size was fixed at $170 \times 90 \mu \mathrm{m}$ throughout the analysis, which yielded 5-10 sampling sites per ROI and assured a suitable sample size. The average mounted section thickness ranged from 16 to $26 \mu \mathrm{m}$ across section series, and disector depth ranged from 14 to $24 \mu \mathrm{m}$. Cells were counted as their top came into focus beneath the top of the disector. The precision of the population estimates was verified using Gundersen's coefficient of error (CE, $m=1$ ) (Gundersen et al., 1999). The CEs obtained from three brains ranged from 0.06 to 0.07 for the total number of sst $_{1}$-positive cells, from 0.05 to 0.06 for the total number of GHRH-positive neurons and from 0.06 to 0.08 for sst ${ }_{1} / \mathrm{GHRH}$ dually positive cells. Means and SEs were calculated using Graph Pad Prism 4.03 (GraphPad Software).

Electron microscopy. Sections were processed for electron microscopic immunostaining using a preembedding procedure as described previously (Dournaud et al., 1998; Boudin et al., 2000; Stroh et al., 2006). Adult male Sprague Dawley rats $(250-325 \mathrm{~g})$ were anesthetized with sodium pentobarbital ( $35 \mathrm{mg} / \mathrm{kg}$, i.v.) and perfused transaortically with $50 \mathrm{ml}$ of heparinized saline $(10 \mathrm{U} / \mathrm{ml}$ in $0.9 \% \mathrm{NaCl})$ followed by 50 $\mathrm{ml}$ of a mixture of $3.75 \%$ acrolein and $2 \%$ PFA in $0.1 \mathrm{M} \mathrm{PB}$, and then by $300 \mathrm{ml}$ of $2 \%$ PFA in $0.1 \mathrm{M} \mathrm{PB}, \mathrm{pH}$ 7.4. Brains were rapidly removed from the skull and postfixed for $30 \mathrm{~min}$ at $4^{\circ} \mathrm{C}$ in the $2 \%$ PFA solution. Sections ( $50 \mu \mathrm{m}$ thick) of the mediobasal hypothalamus were cut on a vibratome, collected in $0.1 \mathrm{M} \mathrm{PB}$, and incubated in a solution of $1 \%$ sodium borohydride in PB for $30 \mathrm{~min}$ to neutralize free aldehyde groups. Following extensive rinsing with $\mathrm{PB}$, they were cryoprotected for $30 \mathrm{~min}$ by immersion in a mixture of $25 \%$ sucrose and $3 \%$ glycerol in $0.1 \mathrm{M} \mathrm{PB}$, rapidly frozen in isopentane at $-60^{\circ} \mathrm{C}$, briefly transferred to liquid nitrogen, and thawed in $0.1 \mathrm{M} \mathrm{PB}$ at room temperature. Sections thus permeabilized by freeze-thaw treatment were preincubated for $30 \mathrm{~min}$ in $0.1 \mathrm{M}$ TBS, pH 7.4, containing $3 \%$ NGS and then incubated overnight at $4{ }^{\circ} \mathrm{C}$ in rabbit sst ${ }_{1} \mathrm{~N}$-terminal antiserum diluted 1:100 in TBS containing $0.5 \%$ NGS. After rinsing in $0.01 \mathrm{M} \mathrm{PBS}$, sections were incubated for $2 \mathrm{~h}$ at RT in a 1:50 dilution of ultrasmall colloidal goldconjugated goat anti-rabbit Ig (Aurion) in PBS containing $0.2 \%$ gelatin and $0.8 \%$ BSA. After several washes in PBS, sections were fixed for $10 \mathrm{~min}$ in $2 \%$ glutaraldehyde in PBS, washed in PBS, and rinsed twice in $0.2 \mathrm{M}$ citrate buffer, $\mathrm{pH}$ 7.4. Immunogold particles were amplified through silver intensification by incubating the sections for $8 \mathrm{~min}$ with IntenSE M silver solution (GE Healthcare). The reaction was stopped by washing in citrate buffer and $0.1 \mathrm{M} \mathrm{PB}, \mathrm{pH}$ 7.4. Subsequent to postfixation in $2 \%$ osmium tetroxide in $0.1 \mathrm{M}$ PB for $40 \mathrm{~min}$, the sections were dehydrated in graded ethanols and infiltrated with a propylene oxide/Epon 812 mixture (1:1 then 1:3, respectively). The mixture was replaced by 100\% Epon 812 and incubated overnight at $4^{\circ} \mathrm{C}$ followed by placement between two sheets of acetate at $60^{\circ} \mathrm{C}$ for $24 \mathrm{~h}$ for flat embedding. Ultrathin sections ( $80 \mathrm{~nm}$ thick) were collected from the ARC (between the retrochiasmatic

\section{Post GH Trough Period}

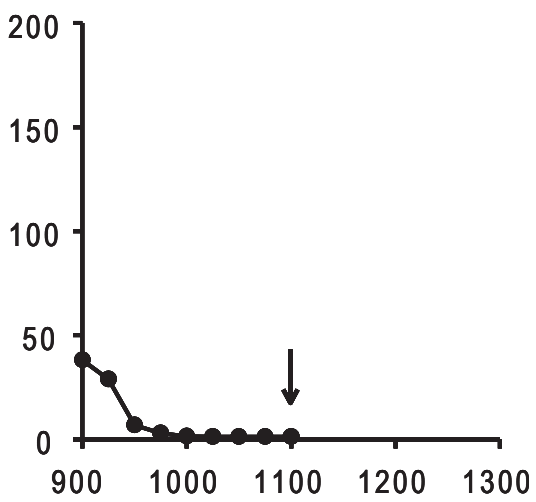

Post GH Peak Period

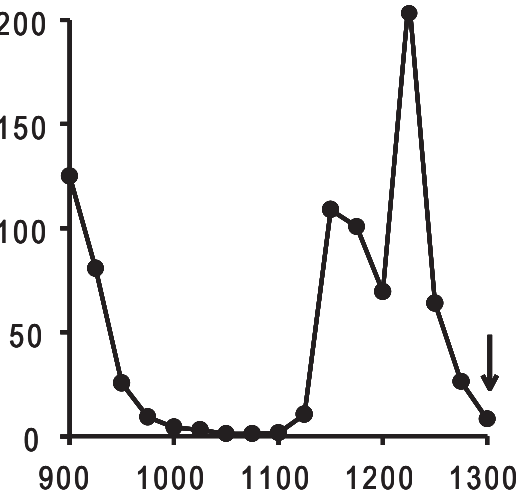

Time (hours)

Figure 1. Ultradian rhythmicity of $\mathrm{GH}$ secretion. Individual representative plasma $\mathrm{GH}$ profiles of two pairs of animals killed at 11:00 A.M. (A) or 1:00 P.M. (B), i.e., after a predicted trough or peak period in plasma $\mathrm{GH}$ concentration (arrows).

area anteriorly and the mammillary bodies posteriorly), counterstained with uranyl acetate/lead nitrate, and examined with a JEOL 100CX transmission electron microscope.

Data analysis. For analysis of the subcellular distribution of silverenhanced gold particles, sections $(\sim 100$ sections in total, collected from two blocks per animal) were randomly scanned, and each field exhibiting gold particles was photographed at an original magnification of 5000$10,000 \times$. Additional sections from tissue incubated in the absence of primary antibodies were also analyzed in each animal to assess nonspecific background labeling. Negatives from electron microscopic photomicrographs were scanned at 1200 dpi resolution on an AGFA Duoscan T1200 scanner (AGFA Canada). The digitized negatives were processed using Adobe Photoshop 6.0 (Adobe Systems) and MS Powerpoint software (Microsoft) on an IBM-compatible computer. Gold particles were then counted and classified according to the type of tissue component, perikarya, terminals, or dendrites, with which they were associated. Dendrite- and cell body-associated grains were further classified as intracellular or membrane associated. Plasma membraneassociated grains overlying or located immediately adjacent to a postsynaptic density or a contact with a presynaptic active zone were scored as "subsynaptic" or "perisynaptic," respectively, and regarded as synapse associated. All morphometry was done using Neurolucida, release 7.0 (MicroBrightField).

Postsynaptic specializations in sst $_{1}$-positive dendritic profiles were identified as open contours using different identifiers for asymmetric and symmetric contacts (respectively). Their lengths as well as the circumference of the dendritic profiles were also determined using Neurolucida 

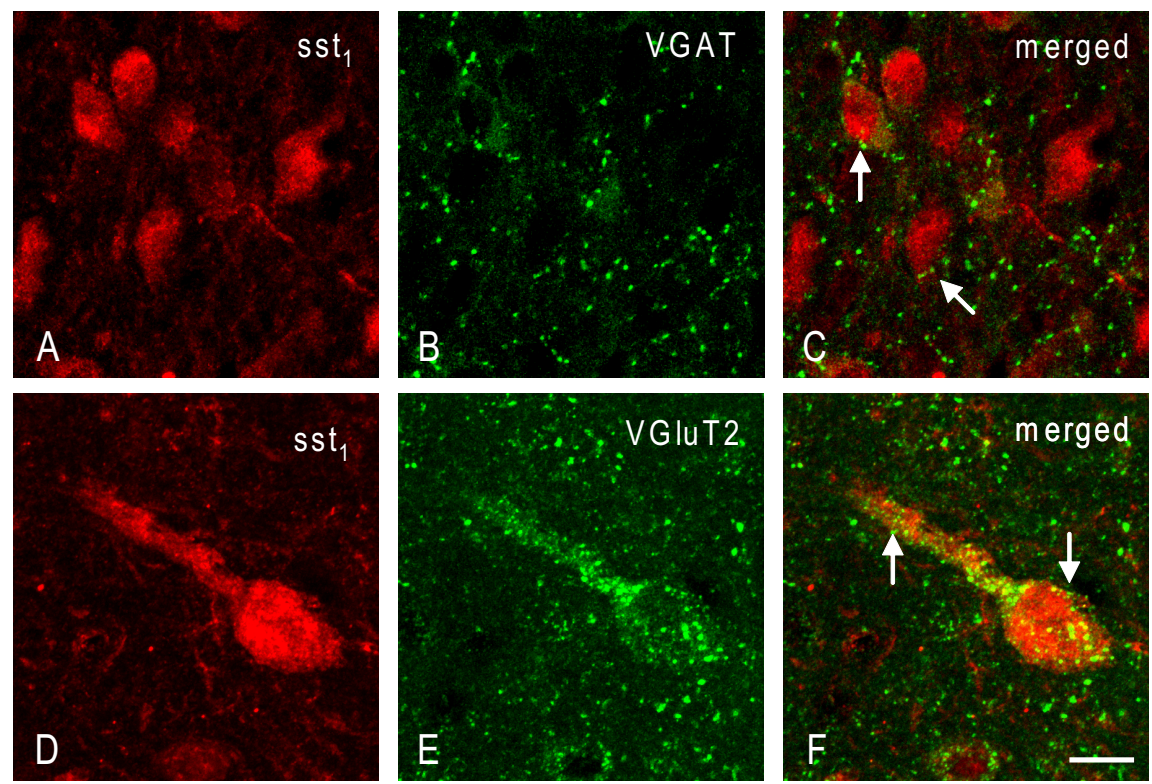

Figure 2. Coronal sections through the rat arcuate nucleus double immunostained for sst 1 and VGAT (A-C) or VGluT2 (D-F). Note the dense innervation of arcuate sst $_{1}$-positive neurons both with VGAT-positive terminals (C, arrows) and terminals positive for VGluT2 (F, arrows). Scale bar: (in $\boldsymbol{F}) \boldsymbol{A}-\boldsymbol{C}, 15 \mu \mathrm{m} ; \boldsymbol{D}-\boldsymbol{F}, 10 \mu \mathrm{m}$.

(MicroBrightField). Calculations were performed using MS Excel 2003 and GraphPad Prism 4.03 (GraphPad Software). All data were normalized and expressed as mean percentages \pm SE. Statistical analyses were performed on both absolute and normalized data, which yielded the same levels of statistical significance. $p \leq 0.05$ was considered significant. Electron microscopic experiments were analyzed using the nonparametric Kruskal-Wallis test followed by group comparisons using either the Mann-Whitney $U$ test or Dunn's multiple-comparison tests. In those studies comparing two groups only, the nonparametric Mann-Whitney $U$ test was used. With respect to GH measurements, Student's two-tailed $t$ test was used for statistical comparison between experimental groups. The integrated area under the GH response curve (AUC) was calculated by the linear trapezoidal method. Results were expressed as the mean $\pm \mathrm{SE}$.

\section{Results}

\section{GH secretion profiles}

Figure 1, $A$ and $B$, illustrates the spontaneous GH secretory profiles of two representative pairs of animals, killed either at the end of a GH trough period (Fig. 1A) or following a GH secretory episode (Fig. $1 B$ ). The typical pulsatile pattern of GH release was observed with high-amplitude GH peaks occurring at the predicted time. The mean AUC for the $2 \mathrm{~h}$ period before the animals were killed was more than threefold lower in animals killed following a GH trough period than that observed in animals killed at the end of a GH secretory episode (mean 2 h GH AUC: $45.0 \pm$ 25.8 vs $142.5 \pm 4.3 \mathrm{ng} / \mathrm{ml} \times \mathrm{h} ; p<0.02)$. Thus, both the GH profiles (Fig. 1) and the corresponding AUC data demonstrate that animals killed at 11:00 A.M. were exposed to a prolonged period of low plasma GH levels before they were killed, whereas animals killed at 1:00 P.M. had completed a full GH secretory episode and were exposed to plasma GH levels as high as 200 $\mathrm{ng} / \mathrm{ml}$ before they were killed.

\section{Immunohistochemistry for $\mathrm{sst}_{1}$, VGluT2, and VGAT in the ARC}

To establish the pattern of distribution of sst $_{1}$ immunoreactivity in the ARC, we incubated frontal sections of rat mediobasal hypothalamus with our $\mathrm{N}$-terminal sst $_{1}$ antiserum, which has been extensively characterized (Stroh et al., 2006). In agreement with previous findings (Stroh et al., 2006), numerous $s t_{1}$-immunopositive neuronal cell bodies were distributed throughout the ARC (supplemental Fig. $1 A$, available at www.jneurosci.org as supplemental material). These sst $_{1}$-positive neurons were particularly densely concentrated in the ventral aspect of the nucleus, where GHRH-producing cells have been reported to be localized (Sasaki et al., 1994; Romero and Phelps, 1997; Tannenbaum et al., 1998). In addition, faint labeling of elongated and punctate structures, reminiscent of dendrites and terminals or cut dendritic profiles, was evident in between the cell bodies (supplemental Fig. 1A, available at www.jneurosci.org as supplemental material).

The ARC is a highly regulated hypothalamic area and receives dense synaptic input. To elucidate the neurochemical identity of synaptic terminals in this region, we incubated parallel sections of mediobasal hypothalamus with antibodies recognizing VGluT2 and VGAT, respectively. In agreement with previous reports (Hrabovszky et al., 2005; Kiss et al., 2006), single labeling for VGluT2 revealed dense VGluT2-positive punctate staining, likely excitatory terminals, throughout the ARC (supplemental Fig. $1 B$, available at www.jneurosci.org as supplemental material). Incubation of parallel sections with an antibody recognizing VGAT demonstrated that the ARC also exhibits densely packed VGATimmunopositive punctate structures, presumably inhibitory synaptic terminals (supplemental Fig. 1C, available at www. jneurosci.org as supplemental material). In fact, VGAT immunoreactivity was so dense that the ARC stood out strikingly from the surrounding hypothalamus (supplemental Fig. 1C, available at www.jneurosci.org as supplemental material). Highmagnification micrographs show that both vesicular neurotransmitter transporter antibodies labeled bead-like structures that tended to encircle what appeared to be neuronal cell bodies in the ARC (supplemental Fig. $1 B, C$, insets, available at www. jneurosci.org as supplemental material).

Double immunofluorescence for sst $_{1}$ and either VGluT2 or VGAT analyzed by confocal microscopy revealed that sst $_{1}$ positive neurons in the ventral ARC appear to be contacted both by numerous VGAT-positive, putatively GABAergic (Fig. $2 A-C$ ) and abundant VGluT2-positive, likely glutamatergic, terminals (Fig. 2D-F).

\section{Immunofluorescence colocalization of sst $_{1}$ and GHRH within ARC neurons}

To show that sst $_{1}$-positive neurons are not only located in the area of the ARC corresponding to the location of GHRH neurons but are also immunoreactive for the neurohormone we double stained sections of mediobasal hypothalamus using our rabbit sst $_{1}$ antiserum and a sheep antiserum against rat GHRH [GRF(129) $\mathrm{NH}_{2}$ ], also previously developed and characterized by us (Tannenbaum et al., 1990). In keeping with our immunohistochemical results, we found sst ${ }_{1}$-positive neurons throughout the ventral ARC (Fig. $3 A$ ), although the labeling was less intense than immunoperoxidase. In addition, moderate numbers of GHRHimmunopositive neurons were distributed in the same area as the 
sst $_{1}$-positive neurons (Fig. $3 B$ ). Almost all of the sst $_{1}$-positive cells were also stained for GHRH (Fig. $3 A, C$, arrowheads). Conversely, a subpopulation of GHRHpositive cells did not colocalize the $\mathrm{sst}_{1}$ protein (Fig. $3 B, C$, arrows). We used unbiased stereological sampling (Optical Fractionator probe) to provide a quantitative estimate of the sst $_{1}$ - and GHRHpositive neuronal populations as well as the number of sst $_{1} / \mathrm{GHRH}$ dually positive cells in the rat ARC. In three individual brains, we found mean numbers \pm SEM of $10,322 \pm 2152$ sst $_{1}$-positive, 12,183 \pm 2580 GHRH-positive, and $9007 \pm 2413$ sst $_{1} / \mathrm{GHRH}$ double-positive neurons in the ARC. These results indicate that $\sim 87 \%$ of ARC neurons expressing the sst $_{1}$ protein also synthesize GHRH and 74\% of GHRH neurons have the $s t_{1}$ receptor.

\section{Subcellular dynamics in the arcuate nucleus in parallel with pulsatile GH secretion}

As in previous studies in the ARC (Stroh et al., 2006), silver-enhanced gold grains indicative of immunoreactive sst $_{1}$ receptors were concentrated over profiles of neuronal cell bodies and dendrites in the ventral ARC (Fig. 4A). In total, 1092 silver/gold particles were analyzed (after peak: 837 ; after trough: 255). Whereas many of these silver particles were located at the plasma membrane (Fig. $4 A$, arrows), the majority was associated with intracellular structures such as Golgi stacks (Fig. 4A, arrowheads) and numerous vesicular organelles. Quantitative analysis revealed that $80 \%$ of the silver/gold particles were intracellular and $20 \%$ located at the plasma membrane (Fig. $4 B)$ ( $n=3$ independent experiments). This ratio was extremely stable throughout the GH secretion cycle; it was completely independent of whether the animal had been killed at the end of a GH trough or a GH peak (Fig. $4 B$ ).

A strikingly large proportion of the plasma membrane-associated sst $_{1}$ receptors were located next to or right on the postsynaptic zone of both symmetric and asymmetric terminals abutting the sst $_{1}$-positive dendritic profiles (Fig. $5 A-D$ ). In contrast to the general subcellular distribution of $s_{1} t_{1}$, this association with synaptic specializations proved to be highly dynamic in parallel with the ultradian rhythm of GH secretion. Thus, $29.9 \%$ of plasma membrane-associated sst $_{1}$ receptors were located at postsynaptic specializations (total: 50 of 167) following GH secretion peak periods, whereas $42.0 \%$ (total: 21 of 50 ) were located at such sites at the end of GH troughs $(p=0.05)$. Independently of the animals' GH status sst ${ }_{1}$ showed a preference for symmetric over asymmetric contacts ( $82 \%$ vs $18 \%$ after peak compared with $76 \%$ vs
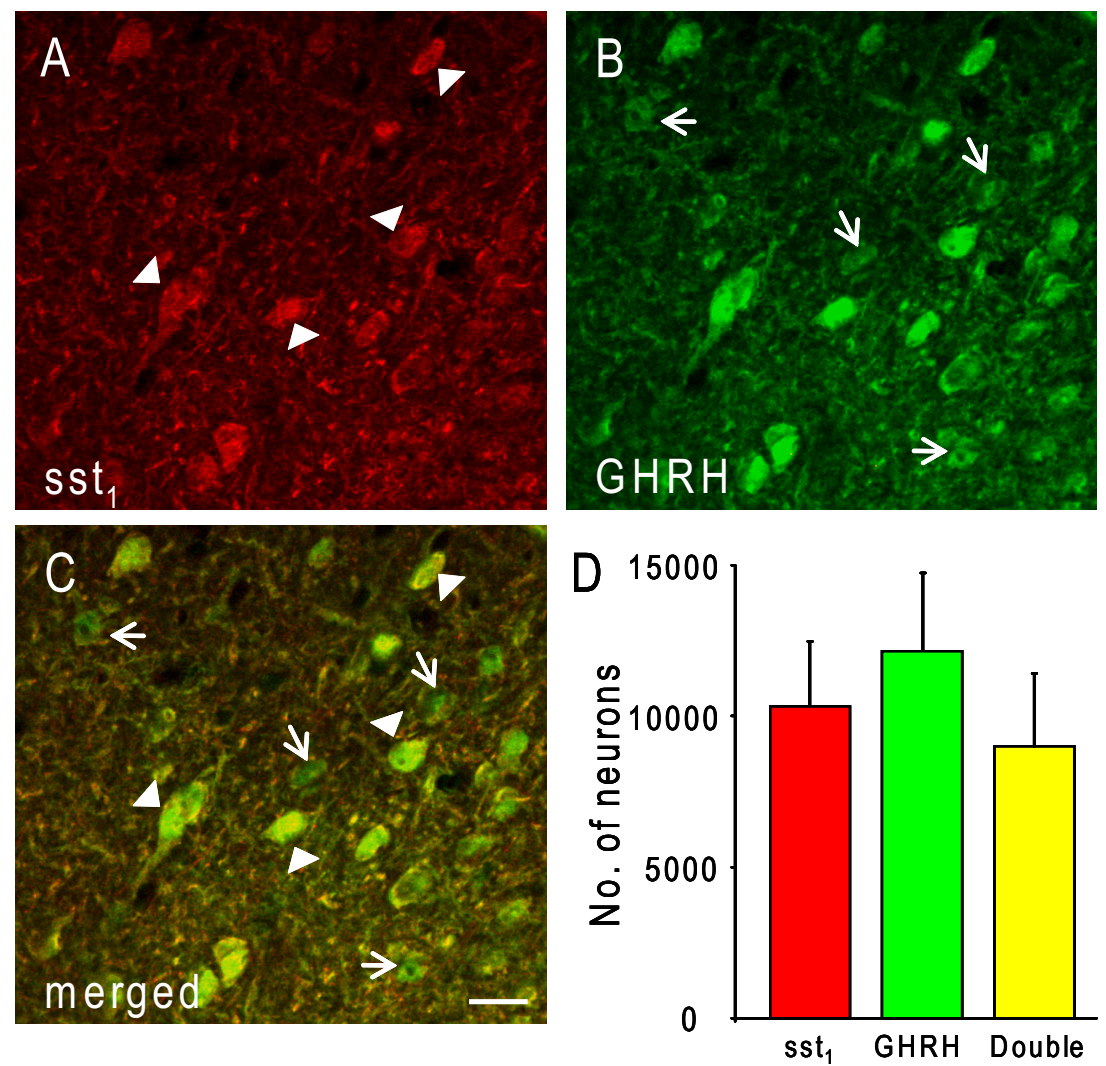

Figure 3. Coronal sections through the rat mediobasal hypothalamus at the level of the ARC. Sections were double stained for

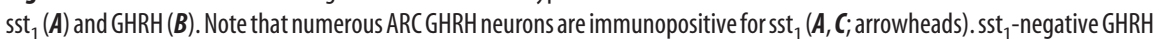
cells are indicated by arrows in $\boldsymbol{B}$ and the merged image ( $\boldsymbol{C}$. The images represent a confocal $z$-stack of 12 optical sections, each $4.7 \mu \mathrm{m}$ thick, which were projected onto one plane and corrected for brightness and contrast using Photoshop CS2. Scale bar, 30 $\mu \mathrm{m}$. D, Unbiased stereological estimates of the numbers of $s_{1} t_{1}$ - and GHRH-immunopositive neurons and neurons double labeled for both the receptor and the peptide ("Double") in the rat ARC. Stereological data represent means \pm SEM from three rats.
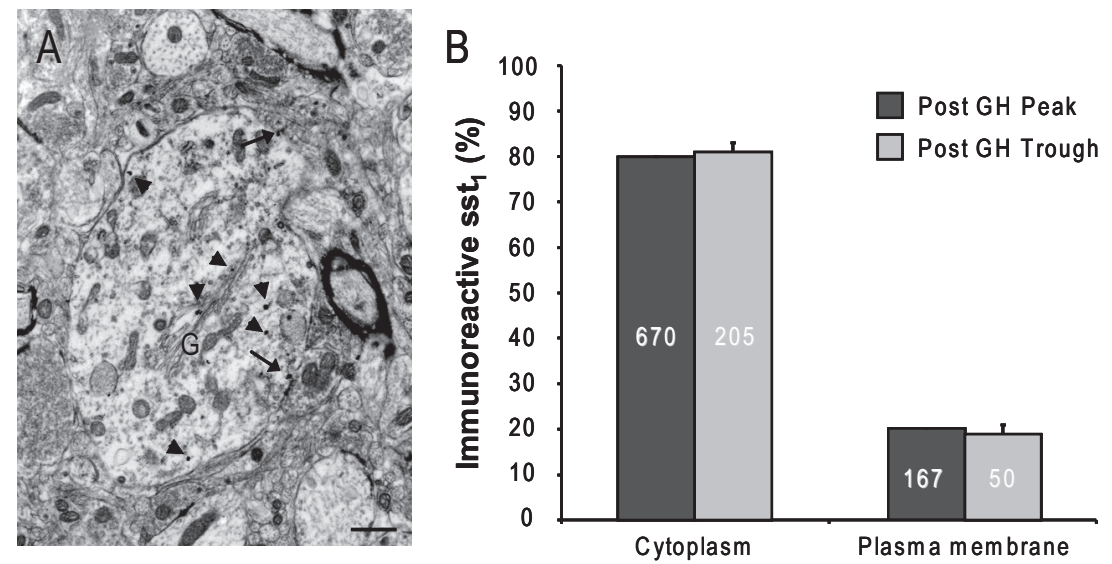

Figure 4. Subcellular distribution of sst $_{1}$ in the arcuate nucleus. $\boldsymbol{A}$, Electron micrograph of an sst ${ }_{1}$-positive dendritic profile. While two silver particles, representing immunoreactive $s_{1}{ }_{1}$ receptors, are located at the plasma membrane (arrows), the bulk of immunoreactivity is found intracellularly (arrowheads), associated with vesicular organelles and, notably, the Golgi apparatus (G). Scale bar, $750 \mathrm{~nm}$. $\boldsymbol{B}$ Quantification of subcellular sst ${ }_{1}$ distribution in animals killed following a GH peak (Post GH Peak) or trough (Post GH Trough), respectively. Data are expressed as percentages of the total number of receptors within each group. Eighty percent of immunoreactive sst ${ }_{1}$ are intracellular and $20 \%$ located at the plasma membrane regardless of GH status. Data represent means \pm SEM; $n=3$ independent experiments. Absolute numbers of immunoreactive receptors are indicated within the columns.

$24 \%$ after trough; $p<0.005$ ) (Fig. 6). Whereas sst $_{1}$ receptors at symmetric synapses were all perisynaptic following a trough in $\mathrm{GH}$ secretion, $15 \%$ were located subsynaptically subsequent to a $\mathrm{GH}$ secretory period ( $p=0.05$ ) (Figs. $5 A, B, 6$ ). In addition, perisynaptic 

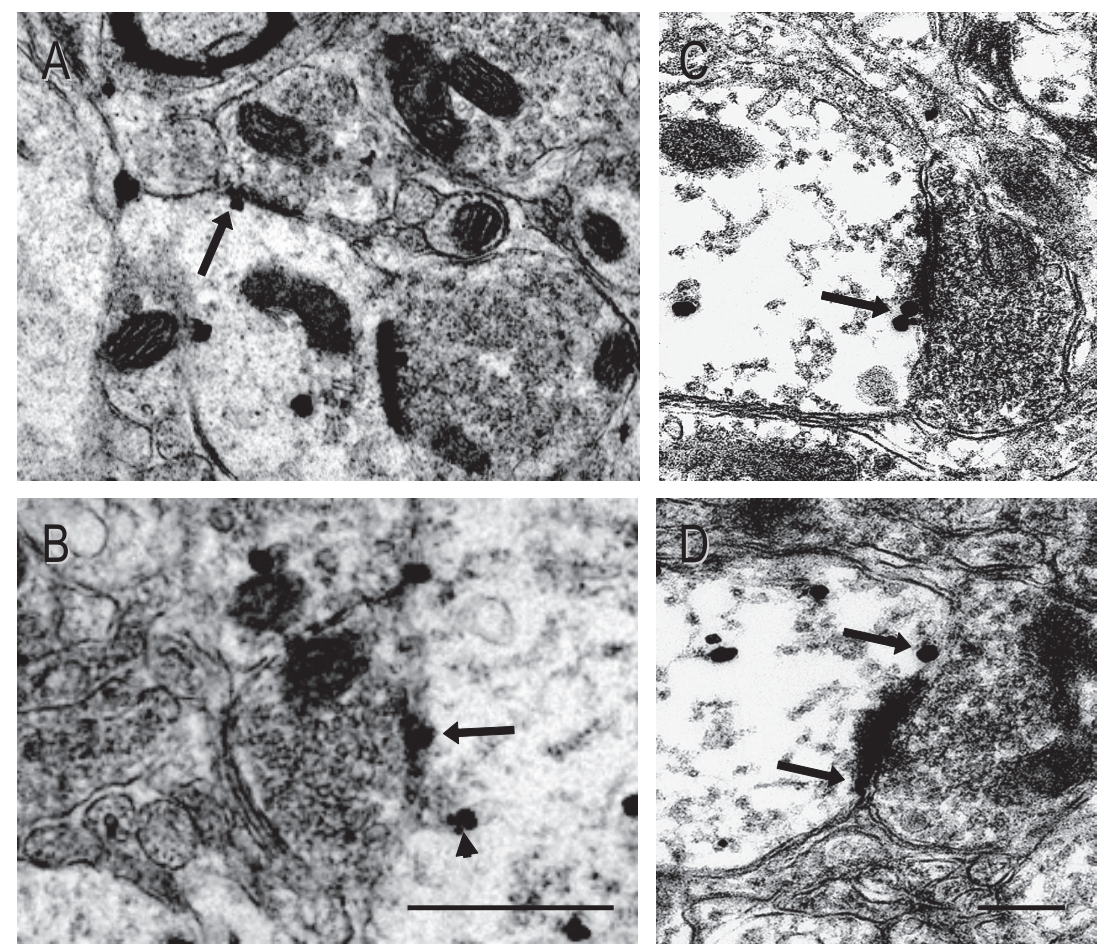

Figure 5. Temporal variation in the localization of sst ${ }_{1}$ at synaptic active zones in relation to the GH cycle. $\boldsymbol{A}-\boldsymbol{D}$, Highmagnification electron micrographs of the arcuate nucleus neuropil immunostained for sst ${ }_{1}$ show that a high proportion of sst receptors at the plasma membrane are located at or next to synaptic contacts (arrows). $\boldsymbol{A}, \boldsymbol{B}$, Examples of plasma membrane sst $_{1}$ receptors at the subsynaptic membrane of symmetric synapses (arrows) in ARC of animals killed at the end of a GH secretion peak.

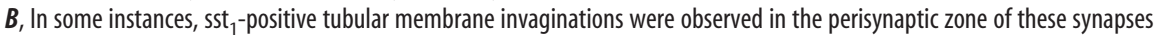
(arrowhead). C, D, Perisynaptic sst ${ }_{1}$ receptors located lateral to the postsynaptic densities of asymmetric synapses. Scale bars: (in B) $\boldsymbol{A}, 180 \mathrm{~nm} ; \boldsymbol{B}, 100 \mathrm{~nm}$; (in D) $\boldsymbol{C}, \boldsymbol{D}, 250 \mathrm{~nm}$.

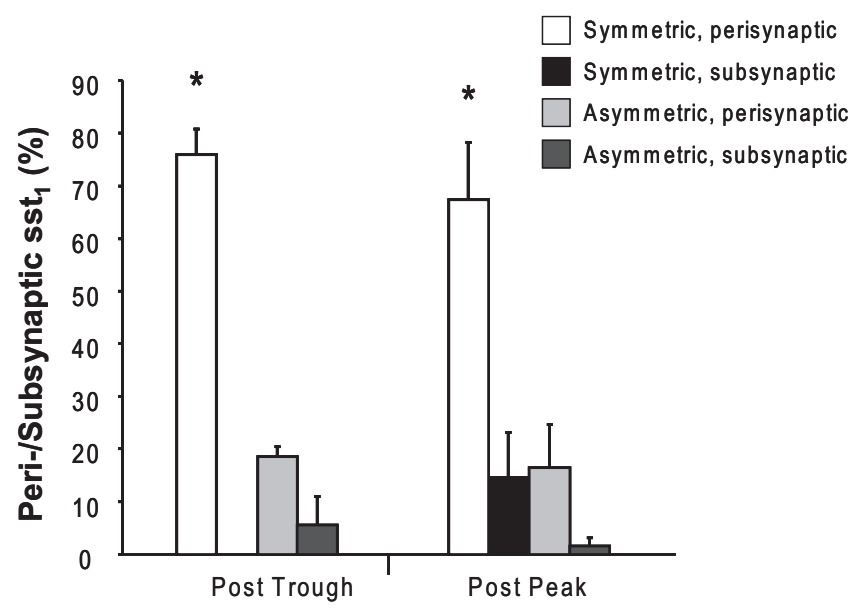

Figure 6. Association of sst $_{1}$ with symmetric as compared with asymmetric synapses. Perisynaptic and synaptic sst ${ }_{1}$ receptors were classified as being associated with a symmetric or an asymmetric synaptic contact following peak (Post Peak) or trough (Post Trough) periods in the $\mathrm{GH}$ secretion cycle. Data represent means \pm SEM of data from three independent experiments $(p<0.005)$. The data are expressed as percentages of all receptors located in perisynaptic or subsynaptic positions following a period of high GH secretion (Post Peak) or a GH trough (Post Trough), respectively. A significant association of sst $_{1}$ receptors with symmetric synapses was observed ( ${ }^{*} p<0.05$ vs all other groups).

membrane invaginations containing immunoreactive sst $_{1}$ were observed at some symmetric synapses (Fig. 5B). In contrast, subsynaptic sst ${ }_{1}$ receptors were found at asymmetric synapses following both $\mathrm{GH}$ trough and peak periods, but their percentage never exceeded 5\% (Fig. 6).
In addition to the synaptic localization of sst ${ }_{1}$ receptors in ARC neurons, synaptic connectivity of the nucleus itself also exhibited ultradian dynamics. Thus, the proportions of asymmetric and symmetric synaptic profiles (as measured by the length of presynaptic and postsynaptic specializations along the dendritic membrane) contacting the circumference of sst $_{1}$-positive profiles, indicative of excitatory and inhibitory innervation, respectively (Uchizono, 1965; Peters et al., 1991), were approximately equal following $\mathrm{GH}$ troughs. However, at the end of a GH secretory episode, $70 \%$ of the contacts were now symmetric, i.e., inhibitory, whereas the percentage of asymmetric synapses dropped to $30 \%(p<0.02)$ (Fig. 7).

\section{Discussion}

In the present study, we demonstrate that somatodendritic sst $_{1}$ SRIF receptors are present in a subset of GHRHimmunopositive neurons of the rat ARC and exhibit an association with postsynaptic specializations that fluctuates in parallel with the ultradian cycle of GH secretion, providing a possible explanation for the ultradian oscillations of SRIF binding in the ARC previously reported (Tannenbaum et al., 1993). We also show that the relative abundance of excitatory and inhibitory inputs to $s_{1}$ $_{1}$-positive neurons in the ARC similarly varies in an ultradian manner dependent on the GH secretion cycle.

Early immunohistochemical studies in the rat found the $s_{1}$ receptor protein restricted to the anterior periventricular nucleus and the median eminence (Helboe et al., 1998). Subsequent studies using different antibodies (Hervieu and Emson, 1998; Stroh et al., 2006; Kumar, 2007) revealed a much wider distribution of the receptor in the rat brain, including the ARC. The distribution of sst $_{1}$ protein demonstrated here conformed to these reports and also to sst ${ }_{1}$ mRNA distribution in the ARC (Pérez et al., 1994; Señarís et al., 1994; Beaudet et al., 1995).

We also showed through unbiased stereological estimation

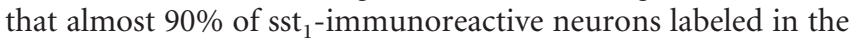
ventral ARC costained for GHRH, as revealed using a previously characterized GHRH antiserum (Tannenbaum et al., 1990). Conversely, $75 \%$ of immunolabeled GHRH neurons were sst $_{1}$ positive, confirming the notion that sst $_{1}$ may be a major player in the mediation of SRIF effects in the central regulation of GH secretion (Tannenbaum and Epelbaum, 1999; Lanneau et al., 2000).

Dual immunostaining using either antibodies recognizing VGluT2 (Fremeau et al., 2001) or antibodies against VGAT (McIntire et al., 1997; Chaudhry et al., 1998) revealed that sst $_{1}$ positive ARC neurons were in close proximity with numerous VGluT2- and VGAT-positive terminals. While these findings do not constitute proof of the presence of synaptic input, due to the resolution limit of light microscopy, they suggest a dense innervation of these ARC neurons by both excitatory and inhibitory terminals.

In keeping with the results of our own previous studies (Stroh et al., 2006), the present electron microscopic observations show that, in neurons of the ARC, immunoreactive sst $_{1}$ receptors are 


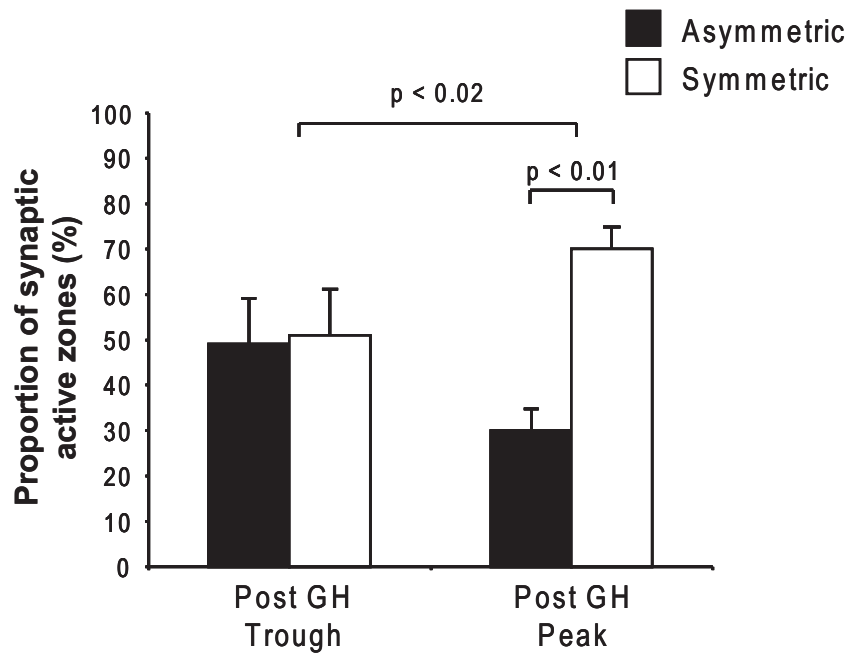

Figure7. Temporal variation in the relative proportions of asymmetric and symmetricsynapses on sst $_{1}$-positive dendritic profiles in the ARC in parallel with the GH rhythm. The proportion of symmetric and asymmetric synapses on sst ${ }_{1}$-positive dendritic profiles in the ARC was quantified on electron micrographs from animals fixed at the end of a trough (Post GH Trough) or peak (Post GH Peak) period of the ultradian GH cycle in male rats ( $p<0.02$ overall; $p<0.01$ comparing asymmetric with symmetric synapses after GH peak, $n=3$ independent experiments).

predominantly localized intracellularly, in association with vesicular organelles ( $80 \%$ intracellular, $20 \%$ on the plasma membrane). Such a pattern of distribution has been described for several GPCRs. For instance, the closely related $s_{2}{ }_{2 \mathrm{~A}}$ receptor subtype is mainly intracellular in brain areas receiving a dense SRIFergic innervation but more heavily surface bound in regions receiving a sparse SRIF innervation (Dournaud et al., 1998). It is therefore conceivable that, as postulated for $\mathrm{sst}_{2}$, the predominantly intracellular localization of sst $_{1}$ observed here may be due to receptor internalization in response to the endogenous agonist since the ARC contains a particularly dense network of SRIF-positive fibers.

The ratio of membrane-associated over intracellular sst ${ }_{1}$ receptors was the same at both times of the ultradian GH cycle examined and conformed to that previously reported in animals of undetermined GH status (Stroh et al., 2006). However, in the present study, a redistribution of cell-surface sst $_{1}$ receptors was observed between $\mathrm{GH}$ peak and trough periods. Whereas $30 \%$ of the plasma membrane-associated $\mathrm{sst}_{1}$ receptors occupied perisynaptic or subsynaptic positions following a period of high $\mathrm{GH}$ secretion, a significantly higher proportion (42\%) was observed at such sites at the end of a GH trough period (low GH release). Although a similar perisynaptic localization has been reported for the metabotropic glutamate receptors mGluR1 and mGluR5 (Luján et al., 1997), this is the first report of an ultradian variation in a GPCR synaptic localization.

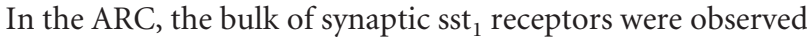
at symmetric (i.e., inhibitory) synapses following $\mathrm{GH}$ peaks. The occasional observation of sst $_{1}$-positive membrane invaginations in perisynaptic position with respect to these sst $_{1}$-labeled symmetric synapses at the end of a GH peak may indicate increased sst $_{1}$ internalization, subsequent to increased SRIF release, at these sites. These results suggest that $s t_{1}$ may play an important role in regulating the inhibition of $\mathrm{GH}$ release by SRIF.

Hypothalamic SRIF release into both the hypophyseal portal circulation and within the ARC is cyclical and exhibits a 3-4 h pattern of release (Plotsky and Vale, 1985; Wagner et al., 1998). At the pituitary level, SRIF interacts with GHRH to regulate somatotropes whereas in the ARC it acts to inhibit GHRH- producing neurons. There is also evidence that within the ARC, GH can influence the expression of $s_{1}$ (but not sst ${ }_{2}$ ) receptors, presumably through SRIF release (Guo et al., 1996). It is therefore tempting to speculate that the cyclical release of SRIF in the ARC might regulate the subcellular localization of $s t_{1}$ receptors in GHRH-producing neurons. Such a mechanism would be in agreement with in vitro studies showing that sst $_{1}$ may be targeted from intracellular stores to the plasma membrane following SRIF stimulation in certain cell types (Ramírez et al., 2005).

In addition to plasticity in the distribution of cell-surface $s t_{1}$ receptors, we observed structural plasticity within the ARC under the influence of the endogenous $\mathrm{GH}$ cycle. sst $_{1}$-immunoreactive dendritic profiles received both numerous asymmetric (Gray type 1) synapses with prominent postsynaptic densities and symmetric (Gray type 2) synapses. However, whereas approximately equal proportions of symmetric and asymmetric synaptic inputs were observed following GH trough periods, this ratio is shifted to 70:30 in favor of symmetric, i.e., inhibitory, inputs after prolonged exposure to high circulating $\mathrm{GH}$, suggesting that a rewiring of the synaptic connectivity has taken place during the $\mathrm{GH}$ peak period. This finding is consistent with reports of various forms of synaptic reorganization in the hypothalamus in response to exogenous signals and endogenous rhythms such as changes in water balance (Miyata et al., 1994; Stern and Armstrong, 1998) or in circulating levels of estradiol (Garcia-Segura et al., 1986; Zsarnovszky et al., 2001; Parducz et al., 2003). Similarly, synaptic plasticity together with changes in the molecular machinery modulating synaptic efficacy may play a key role in the regulation of GH secretion at the level of the hypothalamus.

The present results, together with our previous work (Tannenbaum et al., 1993; Wagner et al., 1998), suggest that at the end of a $\mathrm{GH}$ peak there is an increase in inhibitory synaptic input concomitant with increased concentrations of extracellular SRIF, which are instrumental in terminating the burst of GH secretion and inducing the ensuing trough in the GH cycle. The increase in extracellular SRIF induces a lateral mobilization of perisynaptic sst $_{1}$ receptors to the subsynaptic membrane as well as an increased internalization of $s t_{1}$. As compensation, intracellular sst ${ }_{1}$ receptors are targeted to extrasynaptic plasma membrane sites and are eventually laterally mobilized to replenish the pool of perisynaptic/subsynaptic receptors during the following $\mathrm{GH}$ trough. Such a mechanism would explain our earlier observation that SRIF binding to the ARC is paradoxically highest during $\mathrm{GH}$ peaks (Tannenbaum et al., 1993) as external radioactive ligand has conceivably greater access to nonsynaptic receptors than to spatially restricted synaptic sites.

In conclusion, the results reported here suggest that ARC neurons actively regulate the postsynaptic localization of the $s_{1}$ recep- $_{1}$ tor in conjunction with the ultradian rhythm of the GH secretion cycle. They also indicate that the synaptic connectivity of $\mathrm{sst}_{1}$ positive ARC neurons undergoes pronounced remodeling in parallel with the GH rhythm. Differential modulation of synaptic transmission mediated by $\mathrm{sst}_{1}$ and synaptic remodeling may thus be important mechanisms by which sst $_{1}$ mediates cyclical SRIFergic effects on ARC GHRH neurons in generating the ultradian rhythmicity of GH secretion.

\section{References}

Beaudet A, Greenspun D, Raelson J, Tannenbaum GS (1995) Patterns of expression of SSTR1 and SSTR2 somatostatin receptor subtypes in the hypothalamus of the adult rat: relationship to neuroendocrine function. Neuroscience 65:551-561.

Boudin H, Sarret P, Mazella J, Schonbrunn A, Beaudet A (2000) Somatostatin-induced regulation of $\mathrm{SST}_{2 \mathrm{~A}}$ receptor expression and cell 
surface availability in central neurons: role of receptor internalization. J Neurosci 20:5932-5939.

Chaudhry FA, Reimer RJ, Bellocchio EE, Danbolt NC, Osen KK, Edwards RH, Storm-Mathisen J (1998) The vesicular GABA transporter, VGAT, localizes to synaptic vesicles in sets of glycinergic as well as GABAergic neurons. J Neurosci 18:9733-9750.

Csaba Z, Dournaud P (2001) Cellular biology of somatostatin receptors. Neuropeptides 35:1-23.

Csaba Z, Bernard V, Helboe L, Bluet-Pajot MT, Bloch B, Epelbaum J, Dournaud $P$ (2001) In vivo internalization of the somatostatin sst $2 A$ receptor in rat brain: evidence for translocation of cell-surface receptors into the endosomal recycling pathway. Mol Cell Neurosci 17:646-661.

Csaba Z, Lelouvier B, Viollet C, El Ghouzzi V, Toyama K, Videau C, Bernard V, Dournaud P (2007) Activated somatostatin type 2 receptors traffic in vivo in central neurons from dendrites to the trans Golgi before recycling. Traffic 8:820-834.

Dournaud P, Boudin H, Schonbrunn A, Tannenbaum GS, Beaudet A (1998) Interrelationships between somatostatin sst $2 \mathrm{~A}$ receptors and somatostatin-containing axons in rat brain: evidence for regulation of cell surface receptors by endogenous somatostatin. J Neurosci 18:1056-1071.

Fremeau RT Jr, Troyer MD, Pahner I, Nygaard GO, Tran CH, Reimer RJ, Bellocchio EE, Fortin D, Storm-Mathisen J, Edwards RH (2001) The expression of vesicular glutamate transporters defines two classes of excitatory synapse. Neuron 31:247-260.

Garcia-Segura LM, Baetens D, Naftolin F (1986) Synaptic remodelling in arcuate nucleus after injection of estradiol valerate in adult female rats. Brain Res 366:131-136.

Gundersen HJ, Jensen EB, Kiêu K, Nielsen J (1999) The efficiency of systematic sampling in stereology—reconsidered. J Microsc 193:199-211.

Guo F, Beaudet A, Tannenbaum GS (1996) The effect of hypophysectomy and growth hormone replacement on sst 1 and sst 2 somatostatin receptor subtype messenger ribonucleic acids in the arcuate nucleus. Endocrinology 137:3928-3935.

Helboe L, Stidsen CE, Moller M (1998) Immunohistochemical and cytochemical localization of the somatostatin receptor subtype $s t_{1}$ in the somatostatinergic parvocellular neuronal system of the rat hypothalamus. J Neurosci 18:4938-4945.

Hervieu G, Emson PC (1998) The localization of somatostatin receptor 1 (sst1) immunoreactivity in the rat brain using an $\mathrm{N}$-terminal specific antibody. Neuroscience 85:1263-1284.

Hrabovszky E, Turi GF, Liposits Z (2005) Presence of vesicular glutamate transporter-2 in hypophysiotropic somatostatin but not growth hormone-releasing hormone neurons of the male rat. Eur J Neurosci 21:2120-2126.

Kiss J, Csaba Z, Csáki A, Halász B (2006) Glutamatergic innervation of growth hormone-releasing hormone-containing neurons in the hypothalamic arcuate nucleus and somatostatin-containing neurons in the anterior periventricular nucleus of the rat. Brain Res Bull 70:278-288.

Kumar U (2007) Colocalization of somatostatin receptor subtypes (SSTR1-5) with somatostatin, NADPH-diaphorase (NADPH-d), and tyrosine hydroxylase in the rat hypothalamus. J Comp Neurol 504:185-205.

Lanneau C, Bluet-Pajot MT, Zizzari P, Csaba Z, Dournaud P, Helboe L, Hoyer D, Pellegrini E, Tannenbaum GS, Epelbaum J, Gardette R (2000) Involvement of the Sst1 somatostatin receptor subtype in the intrahypothalamic neuronal network regulating growth hormone secretion: an in vitro and in vivo antisense study. Endocrinology 141:967-979.

Luján R, Roberts JD, Shigemoto R, Ohishi H, Somogyi P (1997) Differential plasma membrane distribution of metabotropic glutamate receptors mGluR1 alpha, mGluR2 and mGluR5, relative to neurotransmitter release sites. J Chem Neuroanat 13:219-241.

McIntire SL, Reimer RJ, Schuske K, Edwards RH, Jorgensen EM (1997) Identification and characterization of the vesicular GABA transporter. Nature 389:870-876.

Miyata S, Nakashima T, Kiyohara T (1994) Structural dynamics of neural plasticity in the supraoptic nucleus of the rat hypothalamus during dehydration and rehydration. Brain Res Bull 34:169-175.

Olias G, Viollet C, Kusserow H, Epelbaum J, Meyerhof W (2004) Regulation and function of somatostatin receptors. J Neurochem 89:1057-1091.

Parducz A, Zsarnovszky A, Naftolin F, Horvath TL (2003) Estradiol affects axo-somatic contacts of neuroendocrine cells in the arcuate nucleus of adult rats. Neuroscience 117:791-794.

Pérez J, Rigo M, Kaupmann K, Bruns C, Yasuda K, Bell GI, Lübbert H, Hoyer D (1994) Localization of somatostatin (SRIF) SSTR-1, SSTR-2 and SSTR-3 receptor mRNA in rat brain by in situ hybridization. Naunyn Schmiedebergs Arch Pharmacol 349:145-160.

Peters A, Palay SL, Webster Hd (1991) The fine structure of the nervous system-neurons and their supporting cells, Ed 3. Oxford: Oxford UP.

Plotsky PM, Vale W (1985) Patterns of growth hormone-releasing factor and somatostatin secretion into the hypophysial-portal circulation of the rat. Science 230:461-463.

Ramírez JL, Watt HL, Rocheville M, Kumar U (2005) Agonist-induced upregulation of human somatostatin receptor type 1 is regulated by betaarrestin-1 and requires an essential serine residue in the receptor C-tail. Biochim Biophys Acta 1669:182-192.

Romero MI, Phelps CJ (1997) Identification of growth hormone-releasing hormone and somatostatin neurons projecting to the median eminence in normal and growth hormone-deficient Ames dwarf mice. Neuroendocrinology 65:107-116.

Sasaki F, Kawai T, Ohta M (1994) Immunohistochemical evidence of neurons with GHRH or LHRH in the arcuate nucleus of male mice and their possible role in the postnatal development of adenohypophysial cells. Anat Rec 240:255-260.

Señarís RM, Humphrey PP, Emson PC (1994) Distribution of somatostatin receptors 1, 2 and 3 mRNA in rat brain and pituitary. Eur J Neurosci 6:1883-1896.

Stern JE, Armstrong WE (1998) Reorganization of the dendritic trees of oxytocin and vasopressin neurons of the rat supraoptic nucleus during lactation. J Neurosci 18:841-853.

Stroh T, Sarret P, Tannenbaum GS, Beaudet A (2006) Immunohistochemical distribution and subcellular localization of the somatostatin receptor subtype 1 (sst1) in the rat hypothalamus. Neurochem Res 31:247-257.

Tannenbaum GS, Epelbaum J (1999) Somatostatin. In: Handbook of physiology - the endocrine system (Kostyo JL, Goodman HM, eds), pp 221265. New York: Oxford UP.

Tannenbaum GS, Ling N (1984) The interrelationship of growth hormone (GH)-releasing factor and somatostatin in generation of the ultradian rhythm of GH secretion. Endocrinology 115:1952-1957.

Tannenbaum GS, Martin JB (1976) Evidence for an endogenous ultradian rhythm governing growth hormone secretion in the rat. Endocrinology 98:562-570.

Tannenbaum GS, McCarthy GF, Zeitler P, Beaudet A (1990) Cysteamineinduced enhancement of growth hormone-releasing factor (GRF) immunoreactivity in arcuate neurons: morphological evidence for putative somatostatin/GRF interactions within hypothalamus. Endocrinology 127:2551-2560.

Tannenbaum GS, Farhadi-Jou F, Beaudet A (1993) Ultradian oscillation in somatostatin binding in the arcuate nucleus of adult male rats. Endocrinology 133:1029-1034.

Tannenbaum GS, Zhang WH, Lapointe M, Zeitler P, Beaudet A (1998) Growth hormone-releasing hormone neurons in the arcuate nucleus express both Sst1 and Sst2 somatostatin receptor genes. Endocrinology 139:1450-1453.

Uchizono K (1965) Characteristics of excitatory and inhibitory synapses in the central nervous system of the cat. Nature 207:642-643.

Wagner C, Caplan SR, Tannenbaum GS (1998) Genesis of the ultradian rhythm of GH secretion: a new model unifying experimental observations in rats. Am J Physiol 275:E1046-E1054.

Zhang WH, Beaudet A, Tannenbaum GS (1999) Sexually dimorphic expression of sst1 and sst2 somatostatin receptor subtypes in the arcuate nucleus and anterior pituitary of adult rats. J Neuroendocrinol 11:129-136.

Zheng H, Bailey A, Jiang MH, Honda K, Chen HY, Trumbauer ME, Van der Ploeg LH, Schaeffer JM, Leng G, Smith RG (1997) Somatostatin receptor subtype 2 knockout mice are refractory to growth hormone-negative feedback on arcuate neurons. Mol Endocrinol 11:1709-1717.

Zsarnovszky A, Horvath TL, Garcia-Segura LM, Horvath B, Naftolin F (2001) Oestrogen-induced changes in the synaptology of the monkey (Cercopithecus aethiops) arcuate nucleus during gonadotropin feedback. J Neuroendocrinol 13:22-28. 